\title{
Distribution and Diversity of Cytochrome P450 Monooxygenases in the Fungal Class Tremellomycetes
}

\author{
Olufunmilayo Olukemi Akapo ${ }^{1}$, Tiara Padayachee ${ }^{1}$, Wanping Chen ${ }^{2}{ }^{10}$,

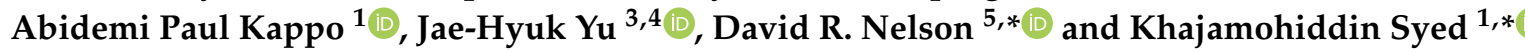 \\ 1 Department of Biochemistry and Microbiology, Faculty of Science and Agriculture, University of Zululand, \\ KwaDlangezwa 3886, South Africa; akapoolufunmilayo@gmail.com (O.O.A.); \\ teez07padayachee@gmail.com (T.P.); KappoA@unizulu.ac.za (A.P.K.) \\ 2 College of Food Science and Technology, Huazhong Agricultural University, Wuhan 430070, China; \\ chenwanping@mail.hzau.edu.cn \\ 3 Department of Bacteriology, University of Wisconsin-Madison, 3155 MSB, 1550 Linden Drive, Madison, \\ WI 53706, USA; jyu1@wisc.edu \\ 4 Department of Systems Biotechnology, Konkuk University, Seoul 05029, Korea \\ 5 Department of Microbiology, Immunology and Biochemistry, University of Tennessee Health Science Center, \\ Memphis, TN 38163, USA \\ * Correspondence: drnelson1@gmail.com (D.R.N.); khajamohiddinsyed@gmail.com (K.S.)
}

Received: 20 April 2019; Accepted: 30 May 2019; Published: 13 June 2019

\begin{abstract}
Tremellomycetes, a fungal class in the subphylum Agaricomycotina, contain well-known opportunistic and emerging human pathogens. The azole drug fluconazole, used in the treatment of diseases caused by some species of Tremellomycetes, inhibits cytochrome P450 monooxygenase CYP51, an enzyme that converts lanosterol into an essential component of the fungal cell membrane ergosterol. Studies indicate that mutations and over-expression of CYP51 in species of Tremellomycetes are one of the reasons for fluconazole resistance. Moreover, the novel drug, VT-1129, that is in the pipeline is reported to exert its effect by binding and inhibiting CYP51. Despite the importance of CYPs, the CYP repertoire in species of Tremellomycetes has not been reported to date. This study intends to address this research gap. Comprehensive genome-wide CYP analysis revealed the presence of 203 CYPs (excluding 16 pseudo-CYPs) in 23 species of Tremellomycetes that can be grouped into 38 CYP families and 72 CYP subfamilies. Twenty-three CYP families are new and three CYP families (CYP5139, CYP51 and CYP61) were conserved across 23 species of Tremellomycetes. Pathogenic cryptococcal species have 50\% fewer CYP genes than non-pathogenic species. The results of this study will serve as reference for future annotation and characterization of CYPs in species of Tremellomycetes.
\end{abstract}

Keywords: cryptococcus; cryptococcus neoformans; cytochrome P450 monooxygenase; CYP51; fungal pathogens; genome data-mining; human pathogens; CYP diversity analysis; tremellomycetes; trichosporon

\section{Introduction}

Cryptococcosis is a fungal infectious disease ubiquitously distributed around the world [1]. Two fungal species, Cryptococcus neoformans and C. gattii, are the main infectious agents causing cryptococcal meningitis in both immunocompetent and immunocompromised humans [1-4]. This disease is the major cause of morbidity and mortality among people living with advanced HIV and annually accounts for $15 \%$ of all HIV-related deaths globally $[5,6]$. The burden of HIV-associated cryptococcal disease in Sub-Saharan Africa is alarming, as 73\% of deaths in the world are reported in this region [5,6]. Apart from these opportunistic pathogens, the genus Cryptococcus contains species with biotechnological potential (Table 1). Among the cryptococcal species, C. amylolentus is closely 
related to the pathogenic $C$. neoformans and is extensively used for comparative studies to identify the pathogenic traits in C. neoformans [7].

The genus Cryptococcus belongs to Tremellomycetes, a fungal class in the subphylum Agaricomycotina, which contains organisms adapted to different niches and/or having different lifestyles (Table 1). Some of the organisms in this class are now regarded as emerging opportunistic human pathogens and some species are adapted to extreme ecological niches, such as cold regions (Table 1). Despite being fungi, Naematella encephala and Tremella mesenterica Fries exhibit fungal parasitism. The diverse lifestyles or characteristics of some species of Tremellomycetes are summarized in Table 1.

Table 1. Some species of Tremellomycetes and their well-known characteristics.

\begin{tabular}{|c|c|c|}
\hline Species Name & Information & References \\
\hline Cryptococcus neoformans & $\begin{array}{c}\text { C. neoformans causes meningitis in immunocompromised } \\
\text { and apparently in immunocompetent humans. } \\
\text { This organism is considered a major opportunistic } \\
\text { pathogen and a leading cause of mortality in patients } \\
\text { infected with HIV. }\end{array}$ & [2] \\
\hline Cryptococcus gattii & $\begin{array}{l}\text { C. gattii causes respiratory (pneumonia) and neurological } \\
\text { (meningoencephalitis) diseases in humans and animals } \\
\text { and it can infect immunocompetent hosts. }\end{array}$ & {$[3,4]$} \\
\hline Cryptococcus terricola JCM 24523 & $\begin{array}{l}\text { C. terricola is oleaginous yeast and has been suggested as a } \\
\text { candidate for the consolidated bioprocessing of } \\
\text { hydrocarbon chemicals. It has the ability to accumulate } \\
\text { unsaturated } 18 \text { carbon chain length fatty acids, with } \\
\text { additional minor contributions of saturated } 18 \text { carbon and } \\
\qquad 16 \text { carbon fatty acids. }\end{array}$ & {$[8-10]$} \\
\hline Cryptococcus curvatus & $\begin{array}{l}\text { C. curvatus is oleaginous yeast capable of accumulating } 18 \\
\text { carbon chain length fatty acids while growing on low or } \\
\text { negative cost feedstock. Thus, it is a potential candidate for } \\
\text { the use in industrial fermentation processes. In a rare case } \\
\text { C. curvatus was found to be involved in peritonitis } \\
\text { associated with gastric lymphoma. }\end{array}$ & {$[8,11,12]$} \\
\hline $\begin{array}{l}\text { Naganishia vishniacii (formerly } \\
\text { known as Cryptococcus vishniacii) }\end{array}$ & $\begin{array}{l}\text { N. vishniacii is psychrophilic yeast adapted to live in } \\
\text { extreme conditions, such as low-temperature oligotrophic } \\
\text { deserts. It also has the ability to grow in a low-nutrient } \\
\text { environment, without added vitamins. }\end{array}$ & {$[8,13,14]$} \\
\hline Cryptococcus wieringae & $\begin{array}{l}\text { This is associated with pectin hydrolysis during the } \\
\text { dew-wetting process of flax and found at the beginning of } \\
\text { grape wine fermentation. }\end{array}$ & {$[8,15]$} \\
\hline Cryptococcus amylolentus CBS 6273 & $\begin{array}{l}\text { C. amylolentus is the most closely known related species of } \\
\text { the pathogenic Cryptococcus species complex, } \\
\text { and is non-pathogenic. }\end{array}$ & {$[7,16]$} \\
\hline $\begin{array}{l}\text { Kockovaella imperatae } \\
\text { NRRL Y-17943 }\end{array}$ & $\begin{array}{l}\text { K. imperatae is a non-pathogenic fungus used in the } \\
\text { analysis of widespread adenine N6-methylation of active } \\
\text { genes in fungal species. }\end{array}$ & [17] \\
\hline Naematella encephela UCDFST & $\begin{array}{l}\text { It is a parasite of another fungus, Stereum sanguinolentum. } \\
\text { This fungus' genome sequencing was carried out for the } \\
\text { analysis of widespread adenine N6-methylation of active } \\
\text { genes in fungal species. }\end{array}$ & [17] \\
\hline
\end{tabular}


Table 1. Cont.

\begin{tabular}{|c|c|c|}
\hline Species Name & Information & References \\
\hline Trichosporon asahii & $\begin{array}{l}\text { Some species belonging to the genus Trichosporon are } \\
\text { considered emerging opportunistic human pathogens and } \\
\text { are the third most commonly isolated non-Candida yeasts } \\
\text { from humans. They live in soil and are adapted to colonize } \\
\text { the skin, gastrointestinal, respiratory and urinary tracts of } \\
\text { humans. T. asahii is the most important species causing } \\
\text { disseminated disease in immunocompromised patients, } \\
\text { while the inhalation of T. asahii spores is the most } \\
\text { important cause of summer-type hypersensitivity } \\
\text { pneumonitis in healthy individuals. Some Trichosporon } \\
\text { species have also emerged as rare but frequently fatal } \\
\text { pathogens causing disseminated infections } \\
\text { (trichosporonosis) in immunocompromised individuals } \\
\text { and intensive care unit patients. }\end{array}$ & [18-20] \\
\hline $\begin{array}{l}\text { Trichosporon oleaginosus } \\
\text { IBC0246 }\end{array}$ & $\begin{array}{l}\text { T. oleaginosus is oleaginous yeast with the ability to } \\
\text { accumulate lipids equivalent to biosynthetic kerosene, } \\
\text { and thus is a biotechnologically valuable player for the } \\
\text { generation of environmentally friendly (carbon-neutral) } \\
\text { energy by converting agro-industrial waste to } \\
\text { fuel (biodiesel). }\end{array}$ & {$[8,21]$} \\
\hline Tremella mesenterica Fries & $\begin{array}{l}\text { It is a parasite of crust fungus of the genus Peniophora and } \\
\text { has a false appearance, as if it were growing on wood. } \\
\text { Whereas in fact, it grows on the crust of fungal mycelium. }\end{array}$ & [22] \\
\hline
\end{tabular}

In countering cryptococcosis, three classes of antifungal agents are available: polyenes (such as amphotericin B), azoles (such as fluconazole) and the pyrimidine analogue to flucytosine [1]. The gold standard induction treatment includes giving amphotericin B along with flucytosine [23]. However, this combination therapy has substantial side effects and the need for intravenous medications poses a problem, as these are not readily available in developing countries, which are most affected by cryptococcosis [24]. To overcome this problem, a combination of fluconazole along with flucytosine has been recommended after initial therapy with amphotericin B and flucytosine $[1,23]$.

Fluconazole binds to the fungal cytochrome $\mathrm{P} 450$ monooxygenase (CYP/P450) enzyme $14 \alpha$-demethylase, named CYP51, which converts lanosterol into ergosterol, an essential component of the fungal cell membrane [25]. C. neoformans also has CYP51 and quite a number of studies have indicated that the development of drug resistance to fluconazole is due to the mutations in the CYP51 gene and to the elevated levels of CYP51 in cryptococcal species [26-30]. In addition to C. neoformans, drug resistance in other species of Tremellomycetes has also been reported owing to mutations in CYP51 [31,32]. Recent studies have demonstrated that the new anti-cryptococcosis drug named VT-1129 that is in the pipeline strongly binds and inhibits CYP51 of C. neoformans and C. gattii [33-35].

Despite the importance of CYPs as drug targets, to date, the CYP repertoire in cryptococcal species or in other species of Tremellomycetes has not been elucidated. A few studies reported the CYP contingent of $C$. neoformans and T. mesenterica Fries with the purpose of comparing the CYP profiles with wood-degrading fungi $[22,36,37]$. Thus, in this study we present a comparative analysis of CYPs in species of Tremellomycetes.

\section{Results and Discussion}

\subsection{Pathogenic Cryptococcal Species Have Few CYPs in Their Genomes}

Genome-wide data mining of CYPs in 16 cryptococcal species revealed the presence of 112 CYPs in their genomes (Figure 1). C. curvatus and C. terricola have the highest number of CYPs (16 CYPs each), and C. gattii VGIV IND107 has the lowest number of CYPs (Figure 1). An interesting pattern was 
observed when comparing the CYP count among cryptococcal species. Almost $50 \%$ fewer CYPs were found in pathogenic cryptococcal species compared to non-pathogenic cryptococcal species (Figure 1). This suggests that adaptation to survive in a host (mainly animals) that has a rich source of simple nutrients might have led to the loss of CYPs. The same phenomenon was observed in fungal species belonging to the subphylum Saccharomycotina, where species lost a considerable number of CYPs owing to their adaptation to simpler carbon sources [38].

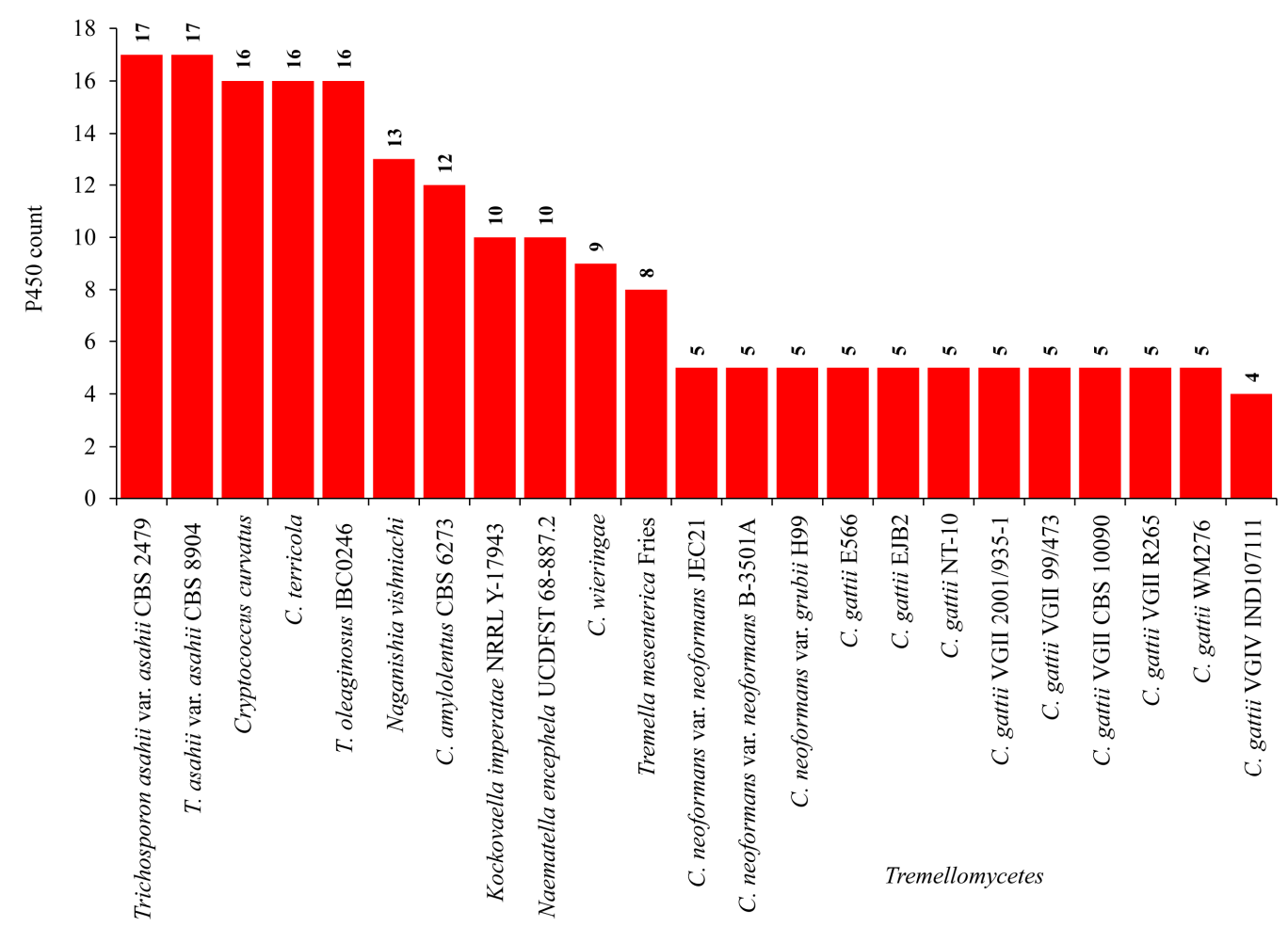

Figure 1. Comparative analysis of CYPs in the species of Tremellomycetes.

The comparison of cryptococcal species' CYP count with other species belonging to the same subphylum Agaricomycotina, especially the well-studied wood-degrading fungi, is not logical, since the wood-degrading species have quite a large number of CYPs in their genomes [22]. As cryptococcal species fall under Tremellomycetes, in this study, a comprehensive comparative analysis of CYPs in Tremellomycetes was carried out (Figure 1). As shown in Figure 1, the comparison of CYPs among species of Tremellomycetes indicated that pathogenic cryptococcal species have a lower number of CYPs compared to other species of Tremellomycetes. Fungal parasites such as T. mesenterica Fries and $N$. encephela have eight and 10 CYPs in their genomes, somewhat lower than non-pathogens. It is interesting to note that the species belonging to the genus Trichosporon have the highest number of CYPs in their genomes, both pathogenic and non-pathogenic (Figure 1). It is well-known that most of the species belonging to this genus are considered commensals of the human skin and gastrointestinal tract, and these species are now increasingly causing superficial and invasive diseases in immunocompromised individuals and intensive care unit patients [18,39]. This indicates that these organisms have a long way to go to adapt better, similar to the cryptococcal species, and thus, in this process they may lose CYPs as well.

\subsection{New CYP Families Were Found in Tremellomycetes}

A total of 203 CYPs were found in 23 species of Tremellomycetes (Figure 2 and Supplementary Dataset 1). Sixteen CYPs were found to be pseudo/false positives, as they lack one of the CYP characteristic motifs and/or short fragments (listed in Supplementary Dataset 1). Thus, these CYPs 
were not included in the study. The annotation of CYPs as per International P450 Nomenclature Committee rules [40-42] in combination with phylogenetic analysis (Figure 2) revealed that 203 Tremellomycetes CYPs could be grouped into 38 CYP families and 72 CYP subfamilies (Figure 2 and Supplementary Dataset 2, sheet 1). Phylogenetic analysis of CYPs is critical in assigning the CYP family and subfamily for the CYPs that have a borderline percentage identity of around $40-41 \%$ (for a family) and $55-56 \%$ (for a subfamily) with the named fungal CYPs.

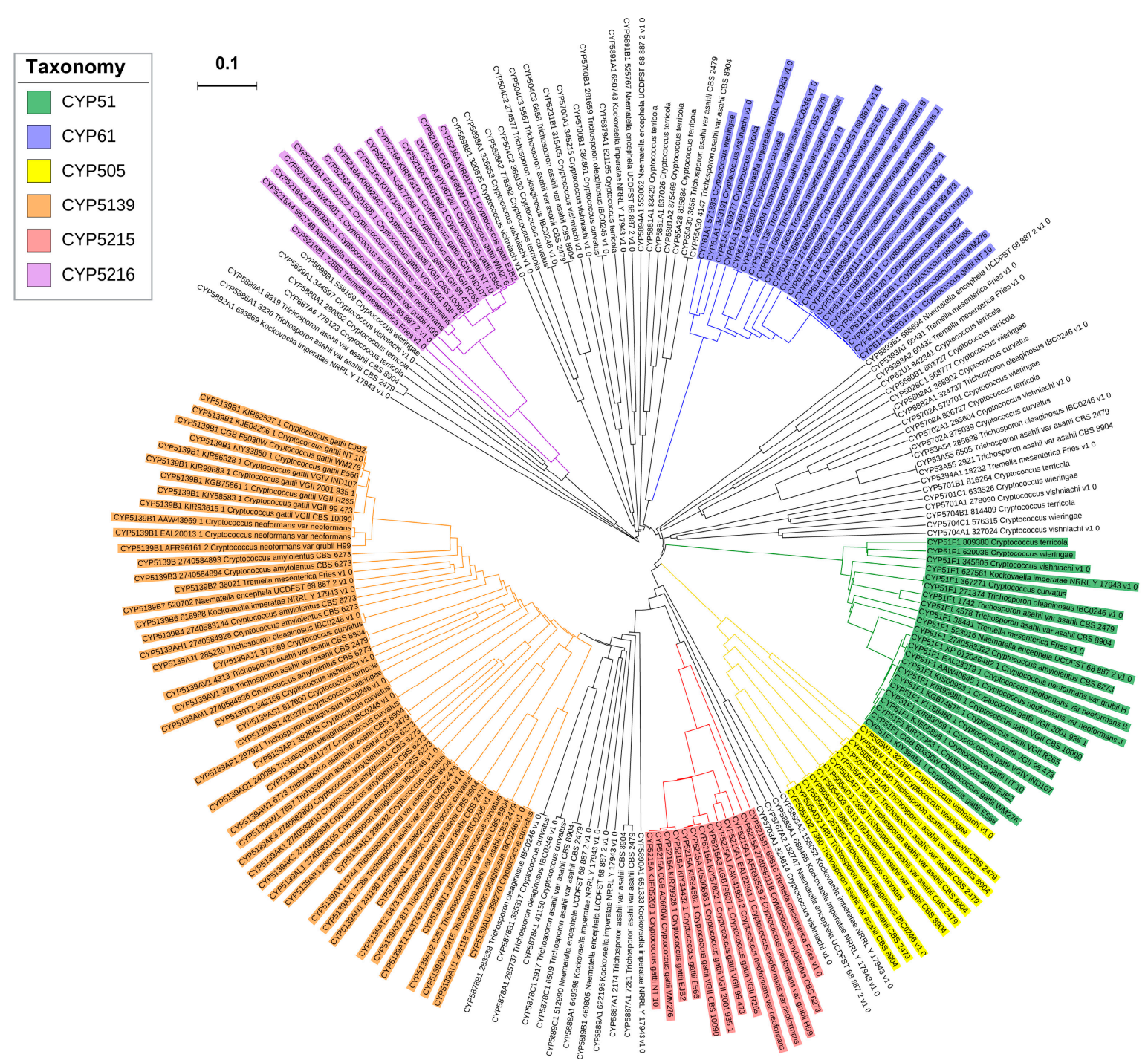

Figure 2. Phylogenetic analysis of CYPs from the species of Tremellomycetes. CYP families that are highly populated in species of Tremellomycetes are indicated in different colors. A high-resolution phylogenetic tree is provided in Supplementary Figure S1.

A total of 23 new CYP families, named CYP5215, CYP5216, CYP5393, CYP5394, CYP5698-CYP5702, CYP5878-CYP5882, and CYP5886-CYP5894A1, were identified in species of Tremellomycetes. Kockovaella imperatae NRRL Y-17943 have the highest number of new CYP families (six CYP families: CYP5888-CYP5893) followed by Naganishia vishniacii (five new CYP families: CYP5698-CYP5702), C. terricola (three new CYP families: CYP5879-CYP5881), T. mesenterica Fries (two new CYP families: CYP5393 and CYP5394), T. oleaginosus IBC0246 (CYP5878 and CYP5882) and two new CYP families (CYP5886 and CYP5887) were found in T. asahii var. asahii CBS 2479 and T. asahii var. asahii CBS 8904. Three species of Tremellomycetes have only one new CYP family: C. neoformans var. grubii H99 (CYP5215), C. neoformans var. neoformans B-3501A (CYP5216), and N. encephela UCDFST 68-887.2 (CYP5894). 


\subsection{Four CYP Families Are Conserved in Pathogenic Cryptococcal Species}

CYP family-level comparative analysis revealed that among 38 CYP families, the CYP5139 family was found to be dominant in species of Tremellomycetes with 51 members, following the CYP51 and CYP61 families each with 23 members, the CYP5216 family with 14 members, the CYP5215 family with 13 members, and the CYP505 family with 12 members (Figure 3). Analysis of CYP family conservation revealed that three CYP families, namely CYP5139, CYP51, and CYP61, are conserved in all 23 species of Tremellomycetes (Figure 4). CYP family comparison among pathogenic cryptococcal species revealed conservation of two more CYP families, CYP5215 and CY5216, in all species except C. gattii VGIV IND107, which does not have CYP5215 (Figure 4). These two CYP families are also present in fungal parasites, T. mesenterica Fries (both families) and N. encephela UCDFST 68-887.2 (only CYP5216 family), and non-pathogenic C. amylolentus CBS 6273 (Figure 4). The CYP family CYP5231 found in N. vishniacii is also present in the fungal species, Melampsora laricis-populina and Puccinia graminis, belonging to the class Pucciniomycotina, where this family is bloomed in both species [36]. The presence of the CYP5126 family only in pathogenic or parasitic Tremellomycetes indicates that this CYP family might be playing a role in the adaptation of these organisms to their host. The analysis of CYP subfamilies revealed that the CYP5139 family has 17 CYP subfamilies, indicating the blooming of members in this family. The same was observed for quite a number of CYP families in other fungi [36,37].

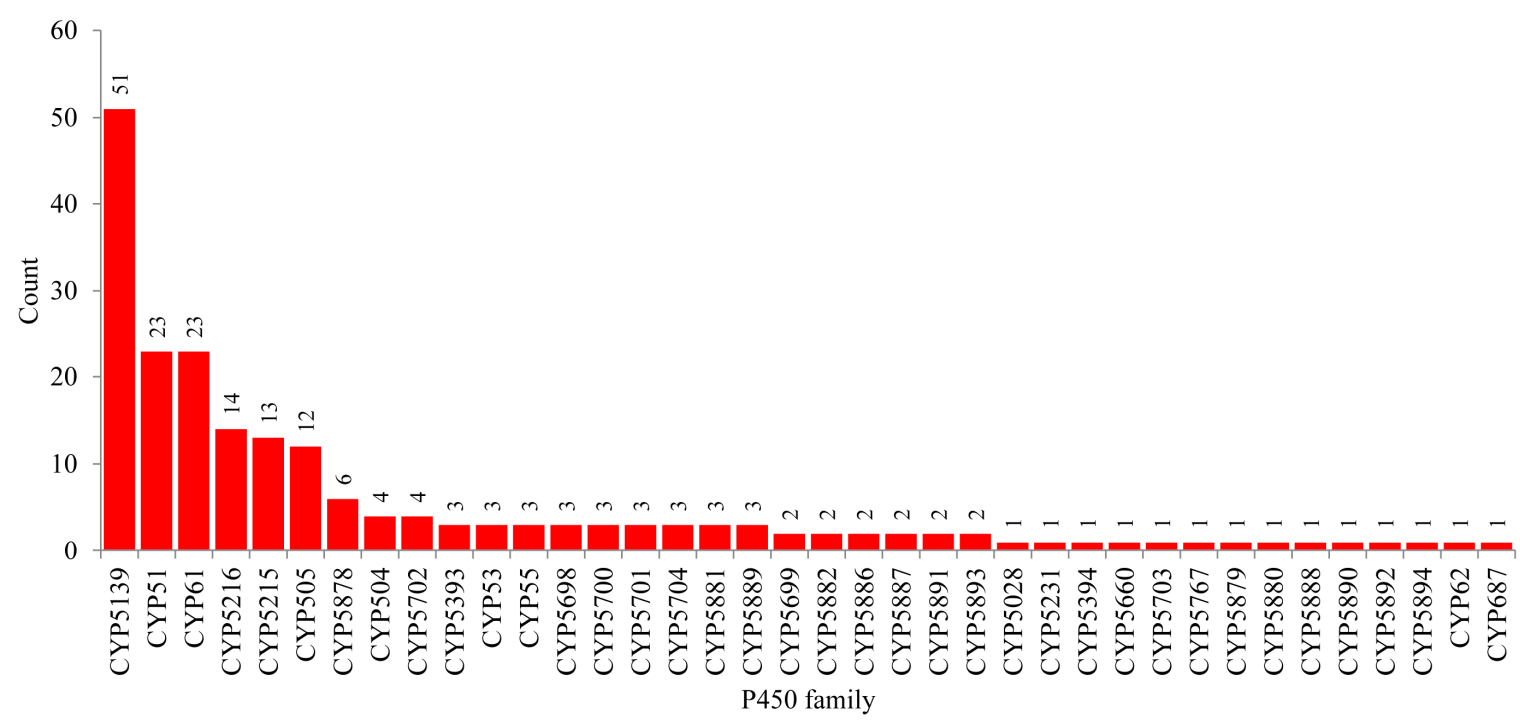

Figure 3. The CYP family-level comparative analysis in the species of Tremellomycetes. The numbers next to the family bar indicate the total number of CYPs. The data on the number of CYPs in each CYP family, along with subfamilies, are presented in Supplementary Dataset 2, sheet 1. 


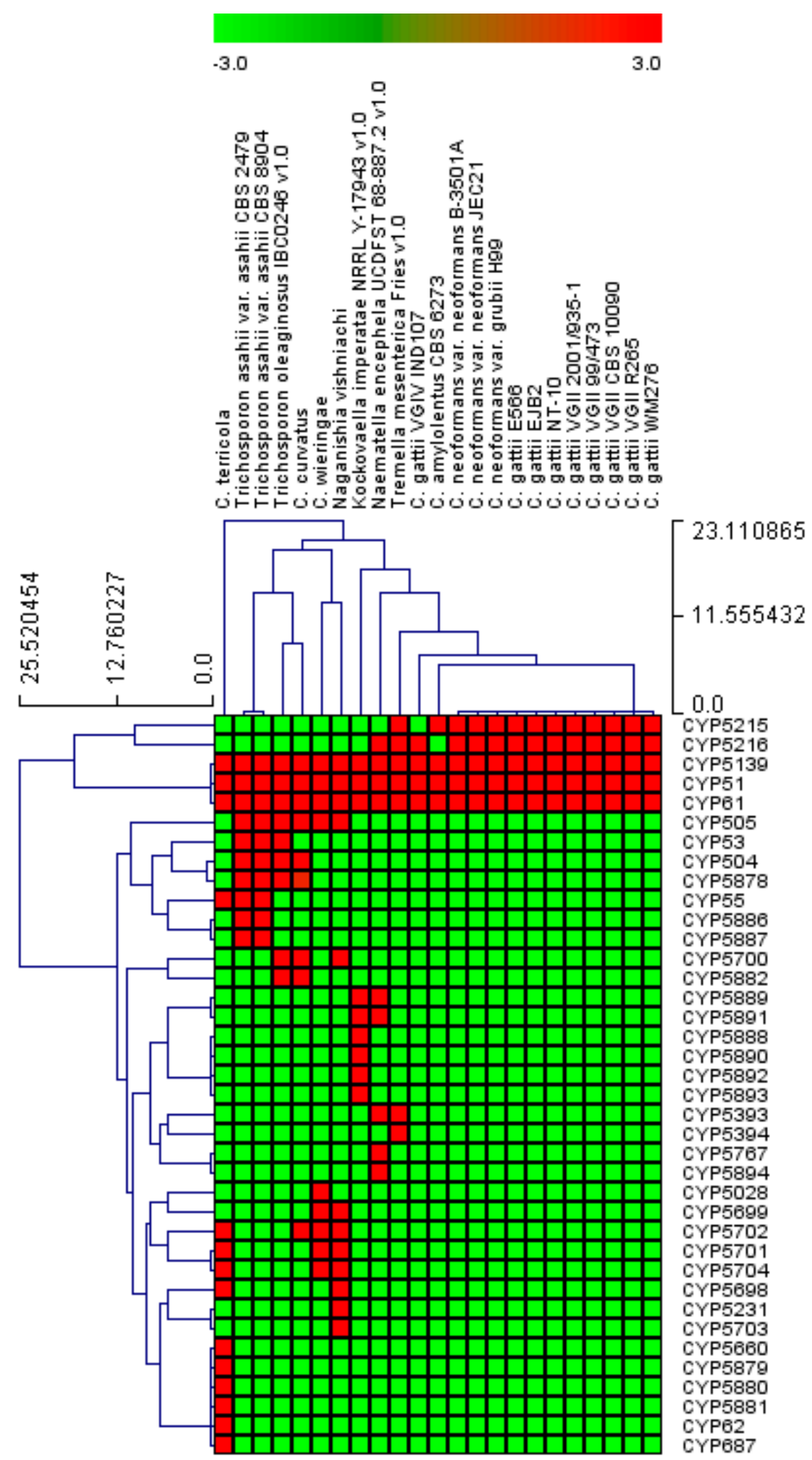

Figure 4. Heat map representing the presence or absence of cytochrome P450 families in 23 species of Tremellomycetes. The data have been represented as -3 for gene absence (green) and 3 for gene presence (red). Twenty-three species of Tremellomycetes form the horizontal axis and CYP families form the vertical axis. The data used in the generation of Figure 4 are presented in Supplementary Dataset 2, sheet 2 . 


\subsection{Pathogenic Cryptococcal Species Have the Highest CYP Diversity}

CYP diversity analysis revealed that pathogenic cryptococcal species, along with non-pathogenic C. wieringae and the fungal parasite $N$. encephela UCDFST 68-887.2, have $100 \%$ CYP diversity in their genomes (Figure 5 and Supplementary Dataset 2, sheet 3). Tremellomycetes such as C. curvatus, C. amylolentus CBS 6273 and T. asahii var. asahii strains had the lowest CYP diversity percentage. This is due to the blooming of CYP5139 members in their genome (Supplementary Dataset 2, sheet 1). The highest CYP diversity observed in pathogenic cryptococcal species is perfectly matched with species belonging to the fungal subphylum Saccharomycotina [38]. One commonality can be found between the species belonging to Tremellomycetes and Saccharomycotina: It can be assumed that some species of Tremellomycetes lost CYPs, compared to their counterparts, which may be due to the adaptation to use simple carbon sources present in the host, as observed for species of Saccharomycotina, where the loss of CYPs in response to the adaptation to use simpler carbon sources was observed [38].

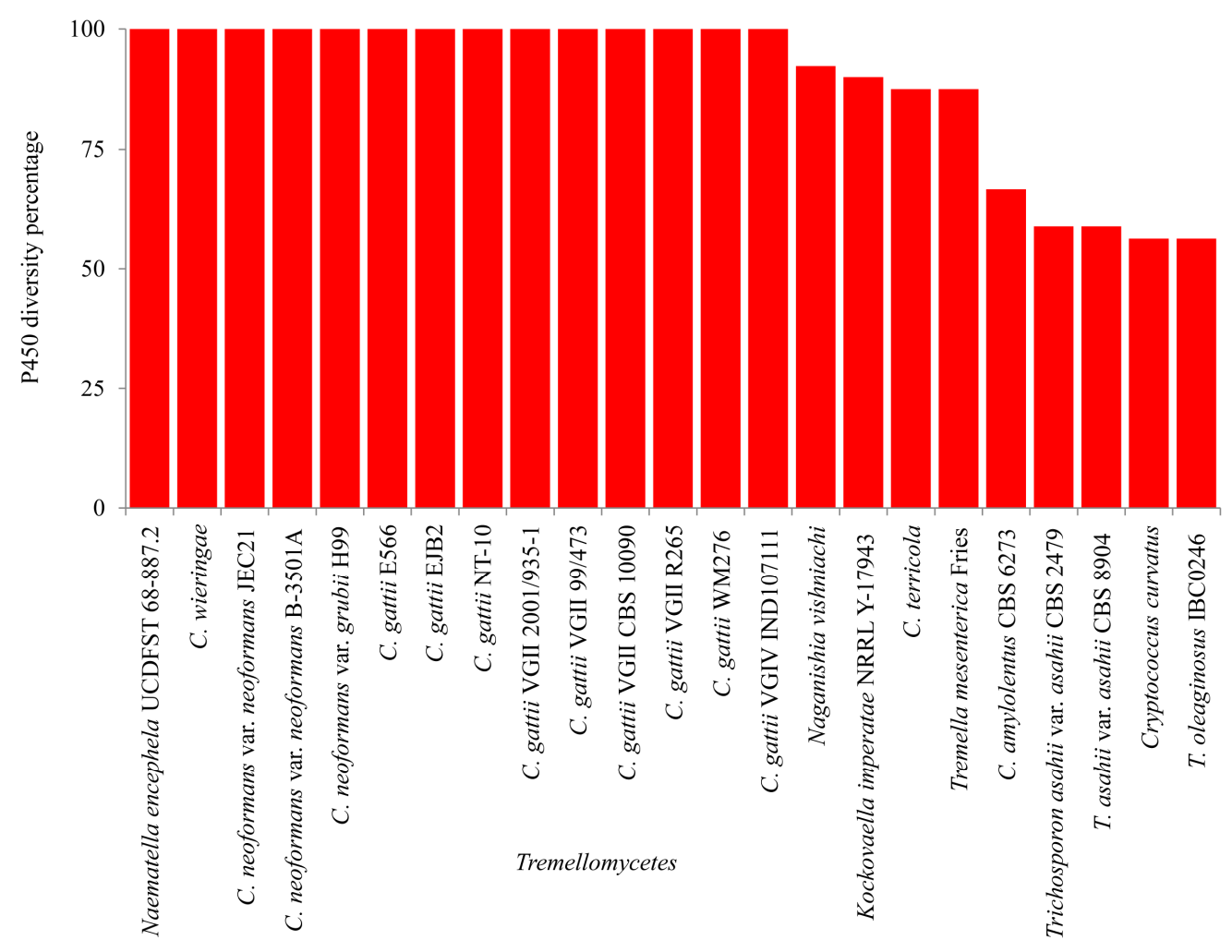

Figure 5. CYP diversity percentage analysis in Tremellomycetes.

\subsection{Most of the CYPs from the Species of Tremellomycetes Are Orphans with No Known Function}

Among CYPs from the species of Tremellomycetes, CYP51F1 of C. neoformans has been shown to be involved in 14 $\alpha$-demethylation of lanosterol [30] and the CYP51F1 gene was cloned from T. asahii ATCC MYA-1296 = OMU239 = TIMM4014 [27]. Apart from CYP51F1, some of the CYPs' functions can be predicted based on characterized homolog CYPs. CYP61 family members are involved in membrane ergosterol biosynthesis where they catalyze C-22 sterol desaturase activity [43]. CYP505 family members are involved in oxidation of fatty acids [44]. CYP504 family members are involved in conversion of phenyl acetate to 2-hydroxyphenylacetate [45]. CYP53 family members are involved in detoxification of toxic molecules, including benzoate and its derived compounds [46-48]. The primary function of CYP53 is the conversion of benzoate to para-hydroxy-benzoate. A study reported that CYP53 could be an alternative antifungal drug target in view of its critical role in fungal organisms [49]. It is interesting to note that this CYP family is only present in three species belonging to the genus Trichosporon (Figure 4 and Supplementary Dataset 2, sheet 1). CYP55 family members are involved in 
the reduction of nitric oxide $(\mathrm{NO})$ to nitrous oxide $\left(\mathrm{N}_{2} \mathrm{O}\right)$ [50,51]. It is interesting to note that in addition to CYP53, CYP55 family members are also found in two species belonging to the genus Trichosporon (Figure 4 and Supplementary Dataset 2, sheet 1). Apart from the CYP families listed above, the rest of the CYPs found in species of Tremellomycetes are orphans.

\section{Materials and Methods}

\subsection{Species and Databases}

Twenty-three species of Tremellomycetes were used in the study (Table 2). Different databases, such as NCBI (https://www.ncbi.nlm.nih.gov/), FungiDB [52] and Joint Genome Institute MycoCosm portal [8], were browsed for cryptococcal species genomes. All the species' genomes used in the study have been published and are available for public use, with the exception of two species, $C$. wieringae and N. vishniacii, and permission to use these two species' CYPs was obtained from the principal investigators listed at the respective species' databases at the Joint Genome Institute MycoCosm portal [8].

Table 2. Species of Tremellomycetes used in the study. The respective genome databases used for analysis of CYPs, along with the reference articles, are listed in the table. Abbreviations: NCBI, National Center for Biotechnology Information and JGI, Joint Genome Institute.

\begin{tabular}{|c|c|c|}
\hline Species Name & Database & Reference \\
\hline Cryptococcus gattii VGII R265 & \multirow{9}{*}{ NCBI } & \multirow{9}{*}[3,4]{} \\
\hline Cryptococcus gattii NT-10 & & \\
\hline Cryptococcus gattii VGII 99/473 & & \\
\hline Cryptococcus gattii E566 & & \\
\hline Cryptococcus gattii VGII 2001/935-1 & & \\
\hline Cryptococcus gattii VGIV IND107 & & \\
\hline Cryptococcus gattii VGII CBS 10090 & & \\
\hline Cryptococcus gattii VGII 2001/935-1 & & \\
\hline Cryptococcus gattii EJB2 & & \\
\hline Cryptococcus gattii WM276 & NCBI & [3] \\
\hline Cryptococcus terricola JCM 24523 v1.0 & JGI & [9] \\
\hline Cryptococcus curvatus ATCC 20509 & JGI & [11] \\
\hline Naganishia vishniacii v1.0 (formerly known as Cryptococcus vishniacii) & JGI & \\
\hline Cryptococcus wieringae & JGI & \\
\hline Cryptococcus neoformans var. neoformans B-3501A & NCBI & [2] \\
\hline Cryptococcus neoformans var. neoformans JEC21 & NCBI & [2] \\
\hline Cryptococcus amylolentus CBS 6273 & JGI & {$[7,16]$} \\
\hline Kockovaella imperatae NRRL Y-17943 v1.0 & JGI & [17] \\
\hline Naematella encephela UCDFST 68-887.2 v1.0 & JGI & [17] \\
\hline Trichosporon asahii var. asahii CBS 2479 & JGI & [19] \\
\hline Trichosporon asahii var. asahii CBS 8904 & JGI & [20] \\
\hline Trichosporon oleaginosus IBC0246 v1.0 & JGI & [21] \\
\hline Tremella mesenterica Fries v1.0 & JGI & [22] \\
\hline Cryptococcus neoformans var. grubii H99 & NCBI & [2] \\
\hline
\end{tabular}




\subsection{CYP Mining and Annotation}

Genome mining for CYPs and subsequent annotation was carried out following the protocol described elsewhere $[36,38,53,54]$. Briefly, proteomes cryptococcal species from different genome databases, listed in Section 3.1, were downloaded and subjected to an NCBI conserved domain search [55] to classify the proteins into different subfamilies. The proteins grouped under a CYP superfamily were selected and subjected to blast analysis against fungal CYPs [42] to identify homolog CYPs. Based on percentage identity with a named homolog CYP, the hit proteins were then assigned to different CYP families and CYP subfamilies, following the International P450 Nomenclature Committee rule, that is, $>40 \%$ identity for a family and $>55 \%$ identity for a subfamily $[40,41]$. CYPs that had less than $40 \%$ identity with named fungal CYPs [42] were assigned to a new family. For each species, CYPs from different databases were compared and duplicate CYPs were removed from the final CYP count.

\subsection{Phylogenetic Analysis of CYPs}

Phylogenetic analysis of CYPs was carried out following the procedure described elsewhere [36,53,56,57]. Briefly, first, the protein sequences were aligned by MAFFT v6.864 [58], and embedded on the T-REX web server [59]. Then, the alignments were automatically subjected to tree inferring and optimization by the T-REX web server. Finally, the best-inferred trees were visualized and colored by iTOL (http://itol.embl.de/about.cgi) [60].

\subsection{Generation of CYP Profile Heat-Maps}

The presence or absence of CYPs in species of Tremellomycetes was shown with heat-maps generated using CYP family data following the method described elsewhere [54,61]. The data were represented as -3 for gene absence (green) and 3 for gene presence (red). A tab-delimited file was imported into multi-experiment viewer (MeV) [62]. Hierarchical clustering using a Euclidean distance metric was used to cluster the data. Twenty-three species of Tremellomycetes form the horizontal axis and $38 \mathrm{CYP}$ families form the vertical axis.

\subsection{CYP Diversity Percentage Analysis}

CYP diversity percentage analysis was carried out as described elsewhere $[53,57,63,64]$. Briefly, the CYP diversity percentage in species of Tremellomycetes was measured as a percentage contribution of the number of CYP families in the total number of CYPs.

\subsection{Functional Prediction of $C Y P s$}

Literature was searched for characterized CYPs from species of Tremellomycetes, if any. Furthermore, functional prediction of CYPs was carried out based on the characterized homolog CYPs from different fungal organisms. CYP family level functional prediction was presented in the article.

\section{Conclusions}

Infections caused by human pathogenic species of Tremellomycetes are regarded as neglected diseases. Research on unraveling the infectious fungal pathogens' physiology and development of novel drugs against these pathogens is seldom done because of the lack of a lucrative market. However, cryptococcal meningitis remains a huge killer among people living with HIV in Sub-Saharan Africa and some of the species in the genus Trichosporon are now emerging human pathogens. This study's results provide insight into the CYP enzymes in the species of Tremellomycetes. This study revealed that cryptococcal species have almost 50\% fewer CYP genes than their non-pathogenic counterparts and furthermore have the highest CYP diversity. Four CYP families were found to be conserved in pathogenic Cryptococcus species, indicating their important role in these pathogens. Interestingly, the CYP5139 family was bloomed with 17 CYP subfamilies in species of Tremellomycetes, indicating its possible key role in the physiology of these organisms. This study serves as a reference for 
future annotation of CYPs and has opened new vistas for the characterization of CYPs in the species of Tremellomycetes.

Supplementary Materials: Supplementary materials can be found at http://www.mdpi.com/1422-0067/20/12/ 2889/s1.

Author Contributions: Conceptualization, K.S.; methodology, O.O.A., T.P., W.C., A.P.K., J.-H.Y., D.R.N. and K.S.; validation, O.O.A., T.P., W.C., A.P.K., J.-H.Y., D.R.N. and K.S.; formal analysis, O.O.A., T.P., W.C., A.P.K., J.-H.Y., D.R.N. and K.S.; investigation, O.O.A., T.P., W.C., A.P.K., J.-H.Y., D.R.N. and K.S.; resources, K.S. and A.P.K.; data curation, O.O.A., T.P., W.C., A.P.K., J.-H.Y., D.R.N. and K.S.; writing—original draft preparation, O.O.A., W.C., J.-H.Y., D.R.N. and K.S.; writing-K.S.; visualization, O.O.A., T.P., W.C., D.R.N. and K.S.; supervision, K.S.; project administration, K.S.; funding acquisition, A.P.K. and K.S.

Funding: Khajamohiddin Syed expresses sincere gratitude to the University of Zululand Research Committee for funding (Grant No. C686) and to the National Research Foundation (NRF), South Africa for a research grant (Grant No. 114159). Tiara Padayachee is grateful to the NRF, South Africa for an honors bursary. Abidemi Paul Kappo is grateful to the South African Medical Research Council (SAMRC) for a research grant (Grant No. PC57009).

Acknowledgments: The authors want to thank Laurie Connell, School of Marine Sciences, The University of Maine, Maine, USA and Joey Spatafora, Dept. Botany \& Plant Pathology, Oregon State University, Oregon, USA for permission to use Naganishia vishniacii (formerly Cryptococcus vishniacii) and Cryptococcus wieringae genome data for CYP analysis. The authors also want to thank Barbara Bradley, Pretoria, South Africa for English language editing.

Conflicts of Interest: The authors declare no conflict of interest. The funders had no role in the design of the study, in the collection, analyses, or interpretation of data, in the writing of the manuscript, or in the decision to publish the results.

\section{References}

1. May, R.C.; Stone, N.R.; Wiesner, D.L.; Bicanic, T.; Nielsen, K. Cryptococcus: from environmental saprophyte to global pathogen. Nat. Rev. Microbiol. 2016, 14, 106-117. [CrossRef] [PubMed]

2. Loftus, B.J.; Fung, E.; Roncaglia, P.; Rowley, D.; Amedeo, P.; Bruno, D.; Vamathevan, J.; Miranda, M.; Anderson, I.J.; Fraser, J.A.; et al. The genome of the basidiomycetous yeast and human pathogen Cryptococcus neoformans. Science 2005, 307, 1321-1324. [CrossRef] [PubMed]

3. D'Souza, C.A.; Kronstad, J.W.; Taylor, G.; Warren, R.; Yuen, M.; Hu, G.; Jung, W.H.; Sham, A.; Kidd, S.E.; Tangen, K.; et al. Genome variation in Cryptococcus gattii, an emerging pathogen of immunocompetent hosts. MBio 2011, 2. [CrossRef] [PubMed]

4. Farrer, R.A.; Desjardins, C.A.; Sakthikumar, S.; Gujja, S.; Saif, S.; Zeng, Q.; Chen, Y.; Voelz, K.; Heitman, J.; May, R.C.; et al. Genome evolution and innovation across the four major lineages of Cryptococcus gattii. MBio 2015, 6. [CrossRef] [PubMed]

5. World Health Organization (WHO). Cryptococcal Disease: What's New and Important. Available online: https://www.who.int/hiv/mediacentre/news/cryptococcal-disease-key-messages/en/ (accessed on 8 April 2019).

6. Rajasingham, R.; Smith, R.M.; Park, B.J.; Jarvis, J.N.; Govender, N.P.; Chiller, T.M.; Denning, D.W.; Loyse, A.; Boulware, D.R. Global burden of disease of HIV-associated cryptococcal meningitis: An updated analysis. Lancet Infect. Dis. 2017, 17, 873-881. [CrossRef]

7. Passer, A.R.; Coelho, M.A.; Billmyre, R.B.; Nowrousian, M.; Mittelbach, M.; Yurkov, A.M.; Averette, A.F.; Cuomo, C.A.; Sun, S.; Heitman, J. Genetic and genomic analyses reveal boundaries between species closely related to Cryptococcus pathogens. bioRxiv 2019. [CrossRef]

8. Kuo, A.; Salamov, A.; Korzeniewski, F.; Nordberg, H.; Shabalov, I.; Dubchak, I.; Otillar, R.; Riley, R.; Ohm, R.; Nikitin, R.; et al. MycoCosm portal: gearing up for 1000 fungal genomes. Nucleic Acids Res. 2013, 42, D699-D704.

9. Close, D.; Ojumu, J.; Zhang, G. Draft genome sequence of Cryptococcus terricola JCM 24523, an oleaginous yeast capable of expressing exogenous DNA. Genome Announc. 2016, 4. [CrossRef]

10. Tanimura, A.; Takashima, M.; Sugita, T.; Endoh, R.; Kikukawa, M.; Yamaguchi, S.; Sakuradani, E.; Ogawa, J.; Ohkuma, M.; Shima, J. Cryptococcus terricola is a promising oleaginous yeast for biodiesel production from starch through consolidated bioprocessing. Sci. Rep. 2014, 4, 4776. [CrossRef]

11. Close, D.; Ojumu, J. Draft Genome sequence of the oleaginous yeast Cryptococcus curvatus ATCC 20509. Genome Announc. 2016, 4. [CrossRef] 
12. Nowicka, J.; Nawrot, U.; Haus, O.; Kuliczkowski, K.; Fonteyne, P.-A.; Nolard, N. Cryptococcus curvatus in peritoneal fluid of gastric lymphoma patient with complex chromosome aberrations-Case report. Med. Mycol. Mikol. 2007, 14, 285-287.

13. Vishniac, H.S.; Hempfling, W.P. Cryptococcus vishniacii sp. nov. an Antarctic yeast. Int. J. Syst. Evol. Microbiol. 1979, 29, 153-158. [CrossRef]

14. Schmidt, S.K.; Vimercati, L.; Darcy, J.L.; Arán, P.; Gendron, E.M.; Solon, A.J.; Porazinska, D.; Dorador, C. A Naganishia in high places: functioning populations or dormant cells from the atmosphere? Mycology 2017, 8, 153-163. [CrossRef] [PubMed]

15. Milanović, V.; Comitini, F.; Ciani, M. Grape berry yeast communities: influence of fungicide treatments. Int. J. Food Microbiol. 2013, 161, 240-246. [CrossRef] [PubMed]

16. Sun, S.; Yadav, V.; Billmyre, R.B.; Cuomo, C.A.; Nowrousian, M.; Wang, L.; Souciet, J.L.; Boekhout, T.; Porcel, B.; Wincker, P.; et al. Fungal genome and mating system transitions facilitated by chromosomal translocations involving intercentromeric recombination. PLoS Biol. 2017, 15, e2002527. [CrossRef] [PubMed]

17. Mondo, S.J.; Dannebaum, R.O.; Kuo, R.C.; Louie, K.B.; Bewick, A.J.; LaButti, K.; Haridas, S.; Kuo, A.; Salamov, A.; Ahrendt, S.R.; et al. Widespread adenine N6-methylation of active genes in fungi. Nat. Genet. 2017, 49, 964-968. [CrossRef] [PubMed]

18. Davies, G.E.; Thornton, C.R. Differentiation of the emerging human pathogens Trichosporon asahii and Trichosporon asteroides from other pathogenic yeasts and moulds by using species-specific monoclonal antibodies. PLoS ONE 2014, 9, e84789. [CrossRef] [PubMed]

19. Yang, R.; Ao, J.; Wang, W.; Song, K.; Li, R.; Wang, D. Disseminated trichosporonosis in China. Mycoses 2003, 46, 519-523. [CrossRef]

20. Yang, R.Y.; Li, H.T.; Zhu, H.; Zhou, G.P.; Wang, M.; Wang, L. Genome sequence of the Trichosporon asahii environmental strain CBS 8904. Eukaryot. Cell 2012, 11, 1586-1587. [CrossRef]

21. Kourist, R.; Bracharz, F.; Lorenzen, J.; Kracht, O.N.; Chovatia, M.; Daum, C.; Deshpande, S.; Lipzen, A.; Nolan, M.; Ohm, R.A.; et al. Genomics and transcriptomics analyses of the oil-accumulating basidiomycete yeast Trichosporon oleaginosus: Insights into substrate utilization and alternative evolutionary trajectories of fungal mating systems. MBio 2015, 6, e00918. [CrossRef]

22. Floudas, D.; Binder, M.; Riley, R.; Barry, K.; Blanchette, R.A.; Henrissat, B.; Martínez, A.T.; Otillar, R.; Spatafora, J.W.; Yadav, J.S. The Paleozoic origin of enzymatic lignin decomposition reconstructed from 31 fungal genomes. Science 2012, 336, 1715-1719. [CrossRef] [PubMed]

23. Perfect, J.R.; Dismukes, W.E.; Dromer, F.; Goldman, D.L.; Graybill, J.R.; Hamill, R.J.; Harrison, T.S.; Larsen, R.A.; Lortholary, O.; Nguyen, M.H.; et al. Clinical practice guidelines for the management of cryptococcal disease: 2010 update by the infectious diseases society of america. Clin. Infect. Dis. 2010, 50, 291-322. [CrossRef] [PubMed]

24. Hanson, K.E.; Catania, J.; Alexander, B.D.; Perfect, J.R. Drug Resistance in Cryptococcosis. In Antimicrobial Drug Resistance: Clinical and Epidemiological Aspects; Mayers, D.L., Sobel, J.D., Ouellette, M., Kaye, K.S., Marchaim, D., Eds.; Springer International Publishing: Cham, Switzerland, 2017; Volume 2, pp. 1119-1140.

25. Kelly, S.L.; Kelly, D.E. Microbial cytochromes P450: biodiversity and biotechnology. Where do cytochromes P450 come from, what do they do and what can they do for us? Philos. Trans. R. Soc. Lond. B Biol. Sci. 2013, 368. [CrossRef] [PubMed]

26. Lamb, D.C.; Corran, A.; Baldwin, B.C.; Kwon-Chung, J.; Kelly, S.L. Resistant P45051A1 activity in azole antifungal tolerant Cryptococcus neoformans from AIDS patients. FEBS Lett. 1995, 368, 326-330. [CrossRef]

27. Sionov, E.; Chang, Y.C.; Garraffo, H.M.; Dolan, M.A.; Ghannoum, M.A.; Kwon-Chung, K.J. Identification of a Cryptococcus neoformans cytochrome P450 lanosterol 14alpha-demethylase (Erg11) residue critical for differential susceptibility between fluconazole/voriconazole and itraconazole/posaconazole. Antimicrob. Agents Chemother. 2012, 56, 1162-1169. [CrossRef] [PubMed]

28. Rodero, L.; Mellado, E.; Rodriguez, A.C.; Salve, A.; Guelfand, L.; Cahn, P.; Cuenca-Estrella, M.; Davel, G.; Rodriguez-Tudela, J.L. G484S amino acid substitution in lanosterol 14-alpha demethylase (ERG11) is related to fluconazole resistance in a recurrent Cryptococcus neoformans clinical isolate. Antimicrob. Agents Chemother. 2003, 47, 3653-3656. [CrossRef] [PubMed]

29. Ngamskulrungroj, P.; Chang, Y.; Hansen, B.; Bugge, C.; Fischer, E.; Kwon-Chung, K.J. Characterization of the chromosome 4 genes that affect fluconazole-induced disomy formation in Cryptococcus neoformans. PLOS ONE 2012, 7, e33022. [CrossRef] 
30. Revankar, S.G.; Fu, J.; Rinaldi, M.G.; Kelly, S.L.; Kelly, D.E.; Lamb, D.C.; Keller, S.M.; Wickes, B.L. Cloning and characterization of the lanosterol 14alpha-demethylase (ERG11) gene in Cryptococcus neoformans. Biochem. Biophys. Res. Commun. 2004, 324, 719-728. [CrossRef]

31. Kushima, H.; Tokimatsu, I.; Ishii, H.; Kawano, R.; Shirai, R.; Kishi, K.; Hiramatsu, K.; Kadota, J. Cloning of the lanosterol 14-alpha-demethylase (ERG11) gene in Trichosporon asahii: A possible association between G453R amino acid substitution and azole resistance in T. asahii. FEMS Yeast Res. 2012, 12, 662-667. [CrossRef]

32. Kushima, H.; Tokimatsu, I.; Ishii, H.; Kawano, R.; Watanabe, K.; Kadota, J.I. A new amino acid substitution at G150S in lanosterol 14-alpha eemethylase (Erg11 protein) in multi-azole-resistant Trichosporon asahii. Med. Mycol. J. 2017, 58, E23-E28. [CrossRef]

33. Lockhart, S.R.; Fothergill, A.W.; Iqbal, N.; Bolden, C.B.; Grossman, N.T.; Garvey, E.P.; Brand, S.R.; Hoekstra, W.J.; Schotzinger, R.J.; Ottinger, E.; et al. The investigational fungal Cyp51 inhibitor VT-1129 demonstrates potent in vitro activity against Cryptococcus neoformans and Cryptococcus gattii. Antimicrob. Agents Chemother. 2016, 60, 2528-2531. [CrossRef] [PubMed]

34. Warrilow, A.G.; Parker, J.E.; Price, C.L.; Nes, W.D.; Garvey, E.P.; Hoekstra, W.J.; Schotzinger, R.J.; Kelly, D.E.; Kelly, S.L. The investigational drug VT-1129 is a highly potent inhibitor of Cryptococcus species CYP51 but only weakly inhibits the human enzyme. Antimicrob. Agents Chemother. 2016, 60, 4530-4538. [CrossRef]

35. Nielsen, K.; Vedula, P.; Smith, K.D.; Meya, D.B.; Garvey, E.P.; Hoekstra, W.J.; Schotzinger, R.J.; Boulware, D.R. Activity of VT-1129 against Cryptococcus neoformans clinical isolates with high fluconazole MICs. Med. Mycol. 2017, 55, 453-456. [PubMed]

36. Qhanya, L.B.; Matowane, G.; Chen, W.; Sun, Y.; Letsimo, E.M.; Parvez, M.; Yu, J.H.; Mashele, S.S.; Syed, K. Genome-wide annotation and comparative analysis of cytochrome P450 monooxygenases in Basidiomycete biotrophic plant pathogens. PLoS ONE 2015, 10, e0142100. [CrossRef] [PubMed]

37. Syed, K.; Shale, K.; Pagadala, N.S.; Tuszynski, J. Systematic identification and evolutionary analysis of catalytically versatile cytochrome P450 monooxygenase families enriched in model basidiomycete fungi. PLoS ONE 2014, 9, e86683. [CrossRef] [PubMed]

38. Kgosiemang, I.K.R.; Syed, K.; Mashele, S.S. Comparative genomics and evolutionary analysis of cytochrome P450 monooxygenases in fungal subphylum Saccharomycotina. J. Pure Appl. Microbiol. 2014, 8, 291-302.

39. Duarte-Oliveira, C.; Rodrigues, F.; Goncalves, S.M.; Goldman, G.H.; Carvalho, A.; Cunha, C. The cell biology of the Trichosporon-host interaction. Front. Cell. Infect. Microbiol. 2017, 7, 118. [CrossRef]

40. Nelson, D.R. Cytochrome P450 nomenclature. Methods Mol. Biol. 1998, 107, 15-24. [PubMed]

41. Nelson, D.R. Cytochrome P450 nomenclature, 2004. Methods Mol. Biol. 2006, 320, 1-10. [PubMed]

42. Nelson, D.R. The cytochrome p450 homepage. Hum. Genom. 2009, 4, 59-65.

43. Kelly, S.L.; Lamb, D.C.; Baldwin, B.C.; Corran, A.J.; Kelly, D.E. Characterization of Saccharomyces cerevisiae CYP61, sterol delta22-desaturase, and inhibition by azole antifungal agents. J. Biol. Chem. 1997, 272, 9986-9988. [CrossRef]

44. Nakayama, N.; Takemae, A.; Shoun, H. Cytochrome P450foxy, a catalytically self-sufficient fatty acid hydroxylase of the fungus Fusarium oxysporum. J. Biochem. 1996, 119, 435-440. [CrossRef]

45. Mingot, J.M.; Penalva, M.A.; Fernandez-Canon, J.M. Disruption of phacA, an Aspergillus nidulans gene encoding a novel cytochrome P450 monooxygenase catalyzing phenylacetate 2-hydroxylation, results in penicillin overproduction. J. Biol. Chem. 1999, 274, 14545-14550. [CrossRef]

46. Faber, B.W.; van Gorcom, R.F.; Duine, J.A. Purification and characterization of benzoate-para-hydroxylase, a cytochrome P450 (CYP53A1), from Aspergillus niger. Arch. Biochem. Biophys. 2001, 394, 245-254. [CrossRef]

47. Matsuzaki, F.; Wariishi, H. Molecular characterization of cytochrome P450 catalyzing hydroxylation of benzoates from the white-rot fungus Phanerochaete chrysosporium. Biochem. Biophys. Res. Commun. 2005, 334, 1184-1190. [CrossRef]

48. Durairaj, P.; Jung, E.; Park, H.H.; Kim, B.G.; Yun, H. Comparative functional characterization of a novel benzoate hydroxylase cytochrome P450 of Fusarium oxysporum. Enzym. Microb. Technol. 2015, 70, 58-65. [CrossRef]

49. Jawallapersand, P.; Mashele, S.S.; Kovacic, L.; Stojan, J.; Komel, R.; Pakala, S.B.; Krasevec, N.; Syed, K. Cytochrome P450 monooxygenase CYP53 family in fungi: Comparative structural and evolutionary analysis and its role as a common alternative anti-fungal drug target. PLoS ONE 2014, 9, e107209. [CrossRef]

50. Nakahara, K.; Tanimoto, T.; Hatano, K.; Usuda, K.; Shoun, H. Cytochrome P-450 55A1 (P-450dNIR) acts as nitric oxide reductase employing NADH as the direct electron donor. J. Biol. Chem. 1993, 268, 8350-8355. 
51. Shoun, H.; Fushinobu, S.; Jiang, L.; Kim, S.W.; Wakagi, T. Fungal denitrification and nitric oxide reductase cytochrome P450nor. Philos. Trans. R. Soc. Lond. B Biol. Sci. 2012, 367, 1186-1194. [CrossRef]

52. Basenko, E.Y.; Pulman, J.A.; Shanmugasundram, A.; Harb, O.S.; Crouch, K.; Starns, D.; Warrenfeltz, S.; Aurrecoechea, C.; Stoeckert, C.J., Jr.; Kissinger, J.C.; et al. FungiDB: An integrated bioinformatic resource for fungi and Oomycetes. J. Fungi 2018, 4, 39. [CrossRef]

53. Matowane, R.G.; Wieteska, L.; Bamal,H.D.; Kgosiemang, I.K.R.; Van Wyk, M.; Manume, N.A.; Abdalla, S.M.H.; Mashele, S.S.; Gront, D.; Syed, K. In silico analysis of cytochrome P450 monooxygenases in chronic granulomatous infectious fungus Sporothrix schenckii: Special focus on CYP51. Biochim. Biophys. Acta Proteins Proteom. 2018, 1866, 166-177. [CrossRef]

54. Ngwenya, M.L.; Chen, W.; Basson, A.K.; Shandu, J.S.; Yu, J.H.; Nelson, D.R.; Syed, K. Blooming of unusual cytochrome P450s by tandem duplication in the pathogenic fungus Conidiobolus coronatus. Int. J. Mol. Sci. 2018, 19, 1711. [CrossRef]

55. Marchler-Bauer, A.; Bo, Y.; Han, L.; He, J.; Lanczycki, C.J.; Lu, S.; Chitsaz, F.; Derbyshire, M.K.; Geer, R.C.; Gonzales, N.R.; et al. CDD/SPARCLE: functional classification of proteins via subfamily domain architectures. Nucleic Acids Res. 2017, 45, D200-D203. [CrossRef]

56. Bamal, H.D.; Chen, W.; Mashele, S.S.; Nelson, D.R.; Kappo, A.P.; Mosa, R.A.; Yu, J.H.; Tuszynski, J.A.; Syed, K. Comparative analyses and structural insights of the novel cytochrome P450 fusion protein family CYP5619 in Oomycetes. Sci. Rep. 2018, 8, 6597. [CrossRef]

57. Senate, L.M.; Tjatji, M.P.; Pillay, K.; Chen, W.; Zondo, N.M.; Syed, P.R.; Mnguni, F.C.; Chiliza, Z.E.; Bamal, H.D.; Karpoormath, R.; et al. Similarities, variations, and evolution of cytochrome P450s in Streptomyces versus Mycobacterium. Sci. Rep. 2019, 9, 3962. [CrossRef]

58. Katoh, K.; Kuma, K.; Toh, H.; Miyata, T. MAFFT version 5: improvement in accuracy of multiple sequence alignment. Nucleic Acids Res. 2005, 33, 511-518. [CrossRef]

59. Boc, A.; Diallo, A.B.; Makarenkov, V. T-REX: A web server for inferring, validating and visualizing phylogenetic trees and networks. Nucleic Acids Res. 2012, 40, W573-W579. [CrossRef]

60. Letunic, I.; Bork, P. Interactive tree of life (iTOL) v3: An online tool for the display and annotation of phylogenetic and other trees. Nucleic Acids Res. 2016, 44, W242-W245. [CrossRef]

61. Mthethwa, B.C.; Chen, W.; Ngwenya, M.L.; Kappo, A.P.; Syed, P.R.; Karpoormath, R.; Yu, J.H.; Nelson, D.R.; Syed, K. Comparative analyses of cytochrome P450s and those associated with secondary metabolism in Bacillus species. Int. J. Mol. Sci. 2018, 19, 3623. [CrossRef]

62. Saeed, A.I.; Sharov, V.; White, J.; Li, J.; Liang, W.; Bhagabati, N.; Braisted, J.; Klapa, M.; Currier, T.; Thiagarajan, M.; et al. TM4: A free, open-source system for microarray data management and analysis. BioTechniques 2003, 34, 374-378. [CrossRef]

63. Parvez, M.; Qhanya, L.B.; Mthakathi, N.T.; Kgosiemang, I.K.; Bamal, H.D.; Pagadala, N.S.; Xie, T.; Yang, H.; Chen, H.; Theron, C.W.; et al. Molecular evolutionary dynamics of cytochrome P450 monooxygenases across kingdoms: Special focus on mycobacterial P450s. Sci. Rep. 2016, 6, 33099. [CrossRef]

64. Sello, M.M.; Jafta, N.; Nelson, D.R.; Chen, W.; Yu, J.H.; Parvez, M.; Kgosiemang, I.K.; Monyaki, R.; Raselemane, S.C.; Qhanya, L.B.; et al. Diversity and evolution of cytochrome P450 monooxygenases in Oomycetes. Sci. Rep. 2015, 5, 11572. [CrossRef]

(C) 2019 by the authors. Licensee MDPI, Basel, Switzerland. This article is an open access article distributed under the terms and conditions of the Creative Commons Attribution (CC BY) license (http://creativecommons.org/licenses/by/4.0/). 